\begin{tabular}{|l|l|}
\hline & $\begin{array}{l}\text { JOURNAL OF SURIMI } \\
\text { SUSTAINABLE RESEARCH IN MANAGEMENT OF AGROINDUSTRI) } \\
\text { Homepage : } \text { https://ejournal.pnc.ac.id/index.php/surimi/index } \\
\text { e-ISSN 2776-7280 dan p-ISSN 2776-7272 }\end{array}$ \\
\hline
\end{tabular}

\title{
Perancangan Design Mesin Pelontar Pakan Ikan Berbasis Mikrokontroler Arduino Mega 2560
}

\section{[Design of Fish Feed Flashing Machine Based On Arduino Mega 2560 Microcontroller]}

\author{
Malik Abdul Aziz ${ }^{1 *}$, Bayu Aji Girawan², Joko Setia Pribadi ${ }^{3}$, Fadillah $^{4}$, Mardiyana ${ }^{5}$ \\ 1,2,3,4,5,6 Politeknik Negeri Cilacap \\ Jl. Dr. Soetomo No.1, Sidakaya-Cilacap 53212 Jawa Tengah, Indonesia \\ * Email korespondensi : maliknanana@gmail.com \\ Dikirim : 2021-12-10 \\ Direvisi : 2021-12-27 \\ Diterima : 2022-01-27
}

\begin{abstract}
Fish feeder machine is a machine designed to perform a feeding process that works automatically according to a predetermined feeding schedule, this machine can help improve efficiency both in terms of feed quantity and time in the feeding process. The purpose of designing and calculating machine elements in this Fish Feeder is to calculate parts of machine elements, determine the concept of machine design, draw machine drawing detail, and determine bill of material. The manufacture of this machine uses approach method of James H Earle and concept selection using the method of Stuart Pugh, drawing software using Solidworks 2015 and working drawing using ISO Standard. The design of the throwing machine that has been made is the result of a literature approach and field surveys (direct surveys at the Fisheries Service and at the Fish Seed Center where fish feed throwing machines are needed). This machine needs a continuous process of development and testing Keywords: design, fish feeding machine.
\end{abstract}

\section{ABSTRAK}

Mesin pelontar pakan ikan adalah mesin yang dirancang untuk melakukan proses pemberian pakan yang bekerja secara otomatis sesuai jadwal pemberian pakan yang telah ditentukan sebelumnya, mesin ini dapat membantu meningkatkan efisiensi, baik dari segi jumlah pakan maupun waktu dalam proses pemberian pakan. Penelitian ini bertujuan untuk membuat desain wujud dan desain detail drawing mesin pelontar pakan ikan. Dalam pembuatan mesin ini menggunakan pendekatan metode perancangan dari James H. Earle dan pemilihan konsep menggunakan metode Stuart Pugh, software gambar menggunakan Solidworks 2015 dan gambar kerja menggunakan standar ISO. Design mesin pelontar yang telah dibuat merupakan hasil pendekatan secara literatur dan survei lapangan (survey langsung di Dinas Perikanan dan di Balai Benih Ikan dimana mesin pelontar pakan ikan ini dibutuhkan). Pada mesin ini perlu proses pengembangan dan pengujian secara terus menerus

Kata kunci: desain, mesin pelontar pakan ikan, pakan ikan, pemberian pakan.

\section{Pendahuluan}

Seiring dengan meningkatnya produksi perikanan dari tahun ke tahun dan target pemerintah untuk menjadikan Negara Indonesia sebagai negara penghasil ikan terbesar di dunia, pembudidaya ikan harus terus mengembangkan hasil produksi budidayanya sehingga mampu memberikan hasil yang diharapkan. Akan tetapi, peternak ikan di Indonesia masih memiliki banyak kendala dalam proses pengembangan, salah satunya yaitu dari segi pemberian pakan ikan. Pakan merupakan faktor penting dalam proses pertumbuhan ikan yang dibudidaya (Ardiwijoyo et al., 2018). Kegiatan pemberian pakan ikan memiliki permasalahan salah satunya yaitu keterlambatan waktu pemberian yang disebabkan. Jika dibiarkan maka dapat membahayakan keadaan serta pertumbuhannya (Yenni \& Benny, 2016).

Pemberian pakan ikan sebagian besar masih menerapkan cara manual sehingga jumlah pakan dalam setiap pemberian porsi pakan berbeda-beda dan tidak stabil. Waktu dalam pemberian pakan ikan 
juga tidak stabil. Pemberian pakan dengan cara manual tersebut memiliki kekurangan yaitu sering terjadi kelalaian pada waktu pemberian pakan dan juga tidak ada pengontrolan takaran pada setiap pemberian pakan. Hal tersebut dapat mengakibatkan pertumbuhan ikan tidak maksimal dan biaya pakan menjadi membengkak. Sebagian besar mesin pelontar pakan yang saat ini sudah ada masih manual dan masih menggunakan tali tambang dan tenaga manusia untuk menggeser dari pinggir tambak ke tengah tambak (Firdaus et al., 2016; Sifa et al., 2020).

Dari permasalahan tersebut maka dibutuhkan desain mesin pelontar pakan ikan yang bekerja secara otomatis sesuai jadwal pemberian pakan yang telah ditentukan sebelumnya dan dapat membantu meningkatkan efisiensi dalam proses pemberian pakan, baik dari segi jumlah pakan maupun waktu. Desain produk merupakan pioner dan kunci keberhasilan sebuah produk agar bisa menembus pasar sehingga dapat disebut sebagai basic bargain marketing, sedangkan mendesain sebuah produk berarti membaca sebuah pasar, kemauan pasar, pola pikir pasar serta masih banyak aspek lainnya yang pada akhirnya akan diterjemahkan dan diaplikasikan dalam merancang pembuatan sebuah produk (Laksana 2014 dalam Ferdiansyah et al., 2020). Perancangan desain mesin pelontar pakan ikan ini diharapkan dapat membentuk desain wujud mesin yang sesuai dengan kebutuhan dan kondisi dilapangan dalam proses pemberian pakan ikan. Mesin pelontar pakan ikan ini mampu melontarkan pakan ikan dengan jumlah yang tetap sehingga mampu membantu meningkatkan efisiensi tenaga manusia dan mampu membantu meningkatkan perkembangkan budidaya ikan. Mesin pelontar pakan ikan ini menggunakan sistem pengendali berbasis mikrokontroler atmega 2560. Penelitian ini bertujuan untuk membuat desain wujud dan desain detail drawing mesin pelontar pakan ikan.

\section{Metodologi Penelitian}

Dalam melakukan perancangan design mesin pelontar pakan ikan ini, peneliti melakukan beberapa prosedur dalam proses perancangan design mesin. Peneliti melakukan pendekatan menggunakan metode perancangan James H. Earle dan penyelesaian menggunakan metode Stuart Pugh, software gambar menggunakan Solidworks 2015 dan gambar kerja menggunakan standar ISO. Secara rinci tahapan prosedur perancangan tersaji pada Gambar 1.

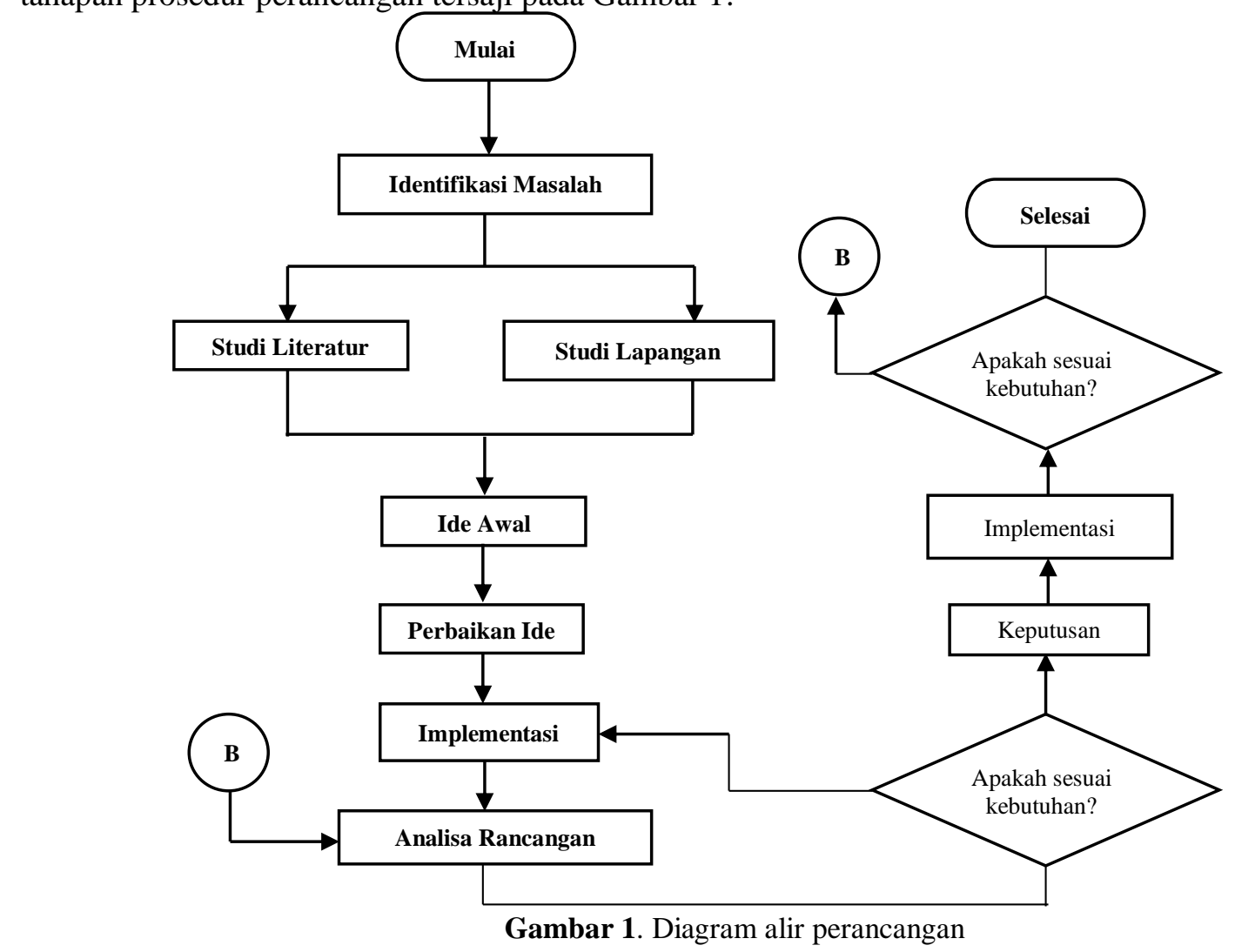

\section{Identifikasi masalah}

Gambar 1. Diagram alir perancangan

Pada tahap ini penulis melakukan kegiatan mengenal atau mencari tahu suatu kebutuhan dan merupakan langkah awal dalam proses perancangan. Pada tahap ini penulis menggunakan metode 
angket jenis terbuka untuk mengetahui kondisi dan masalah yang dihadapi. Adapun tahap-tahap dalam mengidentifikasi masalah yaitu mencari dudukan masalah, menggambarkan masalah untuk memulai proses berpikir, membuat daftar tuntutan, membuat sketsa dan catatan, mengumpulkan data menggunakan metode studi literatur dan survei lapangan (survey langsung di Dinas Perikanan dan di Balai Benih Ikan dimana mesin pelontar pakan ikan ini dibutuhkan).

\section{Ide awal}

Pada tahap ini dalam penentuan ide penulis menggunakan pendekatan secara individu.

\section{Perbaikan ide}

Selanjutnya pada tahap ini persiapan ide yang baik dapat dipilih dengan menyaring untuk menentukan ide yang pantas. Tahap dalam perbaikan ide yaitu mengevaluasi konsep dan memilih konsep yang memenuhi persyaratan menggunakan metode Stuart Pugh, serta memberi bentuk pada konsep yang dipilih berupa alternatif gambar rakitan.

\section{Analisa rancangan}

Membandingkan kelebihan dan kekurangan dari setiap rancangan dengan mempertimbangkan beberapa faktor, meliputi fungsi, manusia, spesifikasi fisik, kekuatan, dan model.

\section{Keputusan}

Setelah melalui analisa rancangan dan pengembangan untuk beberapa desain, kemudian pada tahapan ini penulis memilih salah satu dari desain tersebut untuk diimplementasikan.

a. Mengevaluasi desain menggunakan tabel penilaian yang digunakan untuk perbandingan desain.

b. Menarik kesimpulan apakah desain layak diimplementasikan atau tidak dengan hasil akhir berupa gambar rakitan.

\section{HASIL DAN PEMBAHASAN \\ Identifikasi Masalah}

Pada proses identifikasi masalah kita memerlukan beberapa proses tahapan diantaranya sebagai berikut :

a. Mencari dudukan masalah

Dalam penyelesaian pembuatan penelitian ini kami melakukan wawancara kepada Dinas Perikanan dan Peternakan Kabupaten Banyumas yang beralamat di. Jl. Gatot Subroto. 108. Purwokerto untuk mengetahui kebutuhan akan mesin pelontar pakan ikan yang akan dibuat. Hasil wawancara ditunjukkan pada Tabel 1.

Tabel 1. Hasil Wawancara

\begin{tabular}{|c|c|c|}
\hline No & Pertanyaan & Pernyataan \\
\hline 1. & $\begin{array}{l}\text { Sudah Optimalkah waktu dan frekuensi } \\
\text { proses pemberian pakan ikan selama } \\
\text { ini? }\end{array}$ & $\begin{array}{l}\text { Waktu dalam pemberian pakan ikan masih belum } \\
\text { optimal, karena masih dilakukan oleh tenaga kerja } \\
\text { yang berpatokan pada feeling. }\end{array}$ \\
\hline 2. & $\begin{array}{l}\text { Sudah optimalkah takaran atau dosis } \\
\text { pakan yang diberikan selama pemberian } \\
\text { pakan ikan? }\end{array}$ & $\begin{array}{l}\text { Kurang optimal, karena takaran yang di berikan } \\
\text { selama ini adalah menggunakan feeling dari tenaga } \\
\text { kerja itu sendiri. }\end{array}$ \\
\hline 3. & $\begin{array}{l}\text { Sudah optimalkah hasil dari metode } \\
\text { pemberian pakan ikan yang selama ini } \\
\text { digunakan? }\end{array}$ & $\begin{array}{l}\text { Belum optimal, pertumbuhan pakan ikan tidak } \\
\text { optimal, karena selama selama proses pemberian } \\
\text { pakan ikan, penjadwalan dan dosis pakan ikan yang } \\
\text { tidak teratur }\end{array}$ \\
\hline 4. & $\begin{array}{l}\text { Harapan tentang mesin pelontar pakan } \\
\text { ikan }\end{array}$ & $\begin{array}{l}\text { a. Diciptakannya mesin pelontar pakan ikan dengan } \\
\text { kapasitas penampung pakan yang besar. } \\
\text { b. Diciptakannya mesin pelontar pakan ikan untuk } \\
\text { mempermudah proses pemberian pakan ikan, dari } \\
\text { segi ketepatan waktu dan takan pakan ikan. } \\
\text { c. Mesin mudah dipindah tempatkan (portable). } \\
\text { d. Mesin harus mudah dalam proses } \\
\text { pengoprasiannya. } \\
\text { e. Mesin mudah untuk di bongkar, guna dalam } \\
\text { proses maintenance. } \\
\text { f. Mesin harus memiliki tingkat residu yang rendah. }\end{array}$ \\
\hline
\end{tabular}

b. Membuat daftar tuntutan

Berdasarkan data yang dihimpun dari dudukan masalah dengan hasil wawancara maka dibuatlah 
tabel kebutuhan yang merupakan rangkuman dari beberapa tuntutan konsumen (pengguna) dalam proses pembuatan alat yang akan dibuat dapat dilihat pada Tabel 2.

c. Membuat sketsa dan catatan

Setelah ditentukan kebutuhan konsumen maka dibuatlah sketsa dan catatan untuk alat seperti apa yang harus dibuat. Sketsa dan catatan dapat dilihat pada Tabel 3.

d. Ide Awal

Pada tahapan pembuatan alternatif konsep dari mesin pelontar pakan ikan ini, hanya tertuju pada bagian-bagian tertentu saja yang dirasa paling penting mewakili dari produk yang akan dibuat. Proses pengumpulan ide menggunakan metode Brainstorming yaitu teknik penyelesaian masalah dimana anggota kelompok secara spontan mengungkapkan ide. Dari hasil metode Brainstorming diperoleh ide rancangan dapat dilihat pada Tabel 4.

Tabel 2. Kebutuhan konsumen

\begin{tabular}{|c|l|}
\hline No & \multicolumn{1}{|c|}{ Kebutuhan Konsumen } \\
\hline 1. & Mesin harus dapat mengoptimalkan waktu dan frekuensi proses pemberian pakan ikan. \\
\hline 2. & $\begin{array}{l}\text { Mesin harus dapat mengoptimalkan takaran atau dosis pakan yang diberikan selama } \\
\text { pemberian pakan ikan. }\end{array}$ \\
\hline 3. & $\begin{array}{l}\text { Mesin harus dapat membantu mengoptimalkan petumbuhan pakan ikan, dari segi pemberian } \\
\text { pakan ikan. }\end{array}$ \\
\hline 4. & Mesin harus dapat menampung pakan dengan jumlah yang banyak. \\
\hline 5. & Mesin harus mudah dalam cara pengoperasiannya. \\
\hline 6. & Mesin harus mudah dipindah tempatkan (portable) dan mudah disetting. \\
\hline 7. & Mesin mudah untuk dalam proses perawatan. \\
\hline 8. & Mesin harus memiliki tingkat residu yang rendah. \\
\hline
\end{tabular}

\begin{tabular}{|c|c|c|c|}
\hline No & Spesifikasi Mesin & Sketsa & Catatan \\
\hline 1. & $\begin{array}{l}\text { Mesin dilengkapi dengan timer } \\
\text { otomatis berbasis mikrokontroler. }\end{array}$ & & $\begin{array}{l}\text { Agar operator dapat dengan mudah } \\
\text { dalam mengoprasikan mesin. }\end{array}$ \\
\hline 2. & $\begin{array}{l}\text { Mesin dilengkapi dengan pelontar } \\
\text { yang terpasang pada motor } \\
\text { penggerak yang } \\
\text { dapat melontarkan pakan ikan } \\
\text { minimal sejauh } 1.5 \text { meter. }\end{array}$ & & $\begin{array}{l}\text { Sebagai unit pelontar pada mesin, } \\
\text { pengganti tenaga manusia saat } \\
\text { pemberian pakan ikan. }\end{array}$ \\
\hline 3. & $\begin{array}{l}\text { Mesin dilengkapi dengan unit } \\
\text { pengarah. }\end{array}$ & & $\begin{array}{l}\text { Untuk memutus aliran dan meneruskan } \\
\text { pakan ikan, saat mesin bekerja. }\end{array}$ \\
\hline 4. & $\begin{array}{l}\text { Mesin dilengkapi dengan unit } \\
\text { penampung dengan kapasitas yang } \\
\text { besar. }\end{array}$ & & $\begin{array}{l}\text { Agar mesin dapat menampung pakan } \\
\text { ikan yang banyak, sehingga } \\
\text { meminimalisir pengisian pakan ikan. }\end{array}$ \\
\hline 5. & Mesin dibuat sederhana. & & $\begin{array}{l}\text { a. Agar mesin tidak memakan banyak } \\
\text { tempat. } \\
\text { b. Agar mesin dapat dipindah tempatkan } \\
\text { dan disetting ulang dengan mudah. }\end{array}$ \\
\hline 6. & $\begin{array}{l}\text { Komponen yang dialiri pakan ikan } \\
\text { menggunakan material stainless } \\
\text { steel }\end{array}$ & & $\begin{array}{l}\text { Agar tingkat residu dalam mesin } \\
\text { rendah, sehingga pakan ikan tetap } \\
\text { terjaga kebersihannya. }\end{array}$ \\
\hline
\end{tabular}


e. Perbaikan Ide

Tujuan tahapan ini adalah untuk mempersempit jumlah konsep secara cepat dan untuk memperbaiki konsep.

\begin{tabular}{|c|c|c|c|}
\hline No & Jenis Konsep & Nama Konsep & Sketsa \\
\hline 1. & $\begin{array}{c}\text { Unit } \\
\text { Pengendali }\end{array}$ & $\begin{array}{l}\text { Konsep A } \\
\text { Menggunakan timer otomatis biasa. } \\
\text { Konsep B } \\
\begin{array}{l}\text { Menggunakan timer otomatis berbasis } \\
\text { mikrokontroler. }\end{array}\end{array}$ & 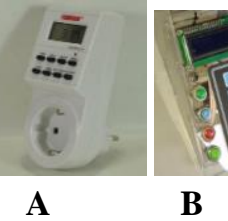 \\
\hline 2. & Cover pelontar & $\begin{array}{l}\text { Konsep A } \\
\text { Cover pelontar tidak dilengkapi dengan pelat } \\
\text { pengarah } \\
\text { Konsep B } \\
\text { Cover pelontar dilengkapi dengan pelat } \\
\text { pengarah }\end{array}$ & $\mathbf{A}$ \\
\hline 3. & $\begin{array}{l}\text { Pengarah } \\
\text { pakan }\end{array}$ & $\begin{array}{l}\text { Konsep A } \\
\text { Penampung pakan tidak di lengkapi dengan } \\
\text { pengaduk. } \\
\text { Konsep B } \\
\begin{array}{l}\text { Penampung pakan dilengkapi dengan } \\
\text { pengaduk }\end{array}\end{array}$ & A \\
\hline 4. & $\begin{array}{c}\text { Penampung } \\
\text { pakan }\end{array}$ & $\begin{array}{l}\text { Konsep A } \\
\text { Penampung pakan menggunakan material full } \\
\text { stainless steel. } \\
\text { Konsep B } \\
\text { Penampung pakan ikan menggunakan drum } \\
\text { plastik. }\end{array}$ & $\mathbf{A}$ \\
\hline 5. & $\begin{array}{l}\text { Rangka kaki } \\
\text { mesin }\end{array}$ & $\begin{array}{l}\text { Konsep A } \\
\text { Bentuk rangka kaki mesin lurus } \\
\text { Konsep B } \\
\text { Bentuk rangka kaki mesin miring. }\end{array}$ & $\mathbf{A}$ \\
\hline 6. & Cover mesin & $\begin{array}{l}\text { Konsep A } \\
\text { Cover mesin yang dilewati pakan ikan } \\
\text { menggunakan pelat besi. } \\
\text { Konsep B } \\
\text { Cover mesin yang dialiri pakan ikan } \\
\text { menggunakan material stainless steel. }\end{array}$ & \\
\hline
\end{tabular}

\section{Pemilihan ide terbaik}

Tahap selanjutnya ide dari hasil Brainstorming dipilih mana yang terbaik. Pada tahap pemilihan ide ini digunakan metode yang telah dikembangkan oleh Stuart Pugh pada tahun 1980 dan sering disebut seleksi konsep Pugh. Tujuan pada proses ini adalah mempersempit jumlah konsep secara cepat dan untuk memperbaiki konsep.

a. Tabel Penilaian

Tabel ini digunakan untuk mempermudah penilaian kriteria dalam pemilihan konsep dalam matrik. Tabel penilaian tersaji pada Tabel 5 .

b. Matrik pemilihan konsep

Setelah penilaian kriteria ditentukan maka tahap selanjutnya adalah membuat matrik pemilihan ide terbaik. Matrik pemilihan ide terbaik dapat dilihat pada Tabel 6 . 
Tabel 5. Penilaian Kriteria

\begin{tabular}{|l|l|}
\hline \multicolumn{1}{|c|}{$\begin{array}{c}\text { Kriteria } \\
\text { Seleksi }\end{array}$} & \multicolumn{1}{|c|}{ Penilaian Berdasarkan } \\
\hline Fungsi & $\begin{array}{l}\text { Suatu mesin atau komponen dapat bekerja sesuai yang } \\
\text { diharapkan }\end{array}$ \\
\hline $\begin{array}{l}\text { Faktor } \\
\text { Manusia }\end{array}$ & $\begin{array}{l}\text { Kenyamanan dan keamanan dalam menggunakan } \\
\text { mesin atau komponen tersebut }\end{array}$ \\
\hline $\begin{array}{l}\text { Spesifikasi } \\
\text { Fisik }\end{array}$ & $\begin{array}{l}\text { Dimensi, beban pada mesin atau komponen yang } \\
\text { digunakan }\end{array}$ \\
\hline Kekuatan & $\begin{array}{l}\text { Dapat menahan getaran, menumpu beban dan } \\
\text { kapasitas benda. }\end{array}$ \\
\hline Model & Bentuk dan rancangan menarik \\
\hline $\begin{array}{l}\text { Faktor } \\
\text { Ekonomi }\end{array}$ & $\begin{array}{l}\text { Proses pembuatan yang murah, mesin dan komponen } \\
\text { tersedia dipasaran. }\end{array}$ \\
\hline
\end{tabular}

Tabel 6. Pemilihan Ide Terbaik

\begin{tabular}{|c|c|c|c|c|c|c|c|c|c|c|c|c|}
\hline \multirow[t]{2}{*}{ Kriteria Seleksi } & \multicolumn{2}{|c|}{ 离 } & \multicolumn{2}{|c|}{ 远离 } & \multicolumn{2}{|c|}{ 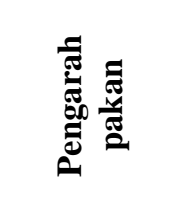 } & \multicolumn{2}{|c|}{ 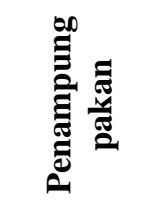 } & \multicolumn{2}{|c|}{ 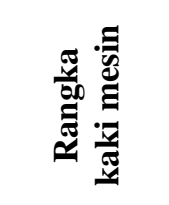 } & \multicolumn{2}{|c|}{ 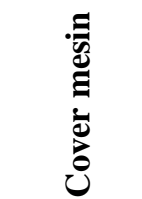 } \\
\hline & $\mathbf{A}$ & B & $\mathbf{A}$ & B & $\mathbf{A}$ & B & $\mathbf{A}$ & B & $\mathbf{A}$ & B & $\mathbf{A}$ & B \\
\hline Fungsi & - & + & - & + & - & + & 0 & 0 & 0 & + & - & + \\
\hline Faktor Manusia & - & + & - & + & - & + & 0 & 0 & - & + & 0 & + \\
\hline Spesifikasi Fisik & 0 & 0 & 0 & 0 & 0 & 0 & 0 & 0 & 0 & 0 & 0 & 0 \\
\hline Kekuatan & 0 & 0 & - & + & - & + & 0 & 0 & - & + & 0 & 0 \\
\hline Model & - & + & - & + & - & + & 0 & + & - & + & 0 & + \\
\hline Faktor Ekonomi & + & - & + & - & + & - & 0 & + & + & - & + & - \\
\hline Total Nilai & -2 & 2 & -3 & 3 & -3 & 3 & 0 & 2 & -2 & 3 & 0 & 2 \\
\hline Lanjutkan? & 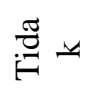 & 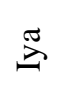 & $\underset{i}{-\frac{\pi}{0}}$ & $\underset{\Xi}{\Xi}$ & $\underset{i}{i}$ & $\underset{\Xi}{\overparen{\Xi}}$ & 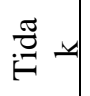 & 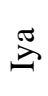 & $\underset{ت}{*}$ & $\underset{\Xi}{\Xi}$ & $\underset{Z}{Z}$ & 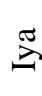 \\
\hline
\end{tabular}

\section{Keterangan :}

a) (+) nilai (1), (0) nilai (0), (-) nilai (-1).

b) Total nilai sama dengan total dari jumlah (+) dengan (-).

Dari hasil penilaian matriks diatas setelah dipilih konsep yang terbaik selanjutnya yaitu penjelasan mengenai gambar rakitan dari komponen konsep yang terpilih.

\section{Gambar rakitan (desain wujud)}

Pada tahap ini konsep yang telah terpilih akan diberi komponen-komponen mesin yang sebelumnya dalam bentuk sketsa, selanjutnya harus diberi bentuk sedemikian rupa sehingga komponen-komponen tersebut menyusun bentuk dan dapat melakukan fungsinya. Gambar rakitan awal mesin dapat dilihat pada Gambar 2.

\section{Analisa Rancangan}

Pada tahap ini setelah konsep terpilih, selanjutnya menganalisa komponen dari alat yang telah di rancang dengan tujuan untuk memeriksa kekurangan pada rancangan agar memperoleh hasil yang terbaik. Analisa rancangan ini berisi kelebihan dan kekurangan dari masing-masing penggunaan komponen mesin. analisa rancangan dapat dilihat pada Tabel 7. 


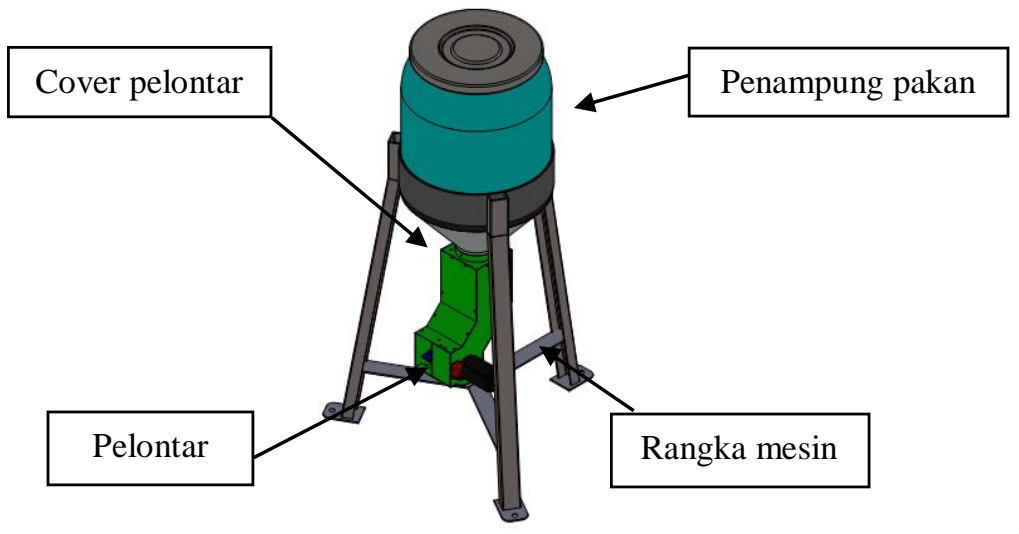

Gambar 2. Gambar rakitan awal mesin.

Tabel 7. Analisa Rancangan

\begin{tabular}{|c|c|c|c|}
\hline No & Rancangan & Kelebihan & Kekurangan \\
\hline \multirow{4}{*}{1} & \multirow{2}{*}{$\begin{array}{c}\text { Unit Pengendali Desain A } \\
\text { A }\end{array}$} & \multicolumn{2}{|c|}{ Menggunakan timer otomatis biasa. } \\
\hline & & - Harga lebih murah & $\begin{array}{l}\text { - Tidak dapat } \\
\text { dikombinasikan dengan } \\
\text { sensor lainnya. } \\
\text { - Sulit pengoprasian. }\end{array}$ \\
\hline & \multirow{2}{*}{ Unit Pengendali Desain B } & \multicolumn{2}{|c|}{ Menggunakan timer otomatis berbasis mikrokontroler. } \\
\hline & & $\begin{array}{l}\text { - Mudah dalam pengoprasian. } \\
\text { - Dapat di kombinasikan } \\
\text { dengan sensor tambahan. }\end{array}$ & $\begin{array}{l}\text { - Harga lebih mahal. } \\
\text { - Pembuatan lebih sulit }\end{array}$ \\
\hline \multirow{4}{*}{2.} & \multirow{2}{*}{$\begin{array}{c}\text { Cover unit pelontar } \\
\text { Desain A }\end{array}$} & \multicolumn{2}{|c|}{ Cover pelontar tidak di lengkapi dengan pelat pengarah } \\
\hline & & $\begin{array}{l}\text { - Lebih hemat biaya. } \\
\text { - Pembuatan cover lebih } \\
\text { mudah }\end{array}$ & $\begin{array}{l}\text { - Lebih hemat biaya. } \\
\text { - Aliran pakan ikan tidak } \\
\text { teratur. }\end{array}$ \\
\hline & \multirow[t]{2}{*}{$\begin{array}{l}\text { Cover unit pelontar } \\
\text { Desain B }\end{array}$} & \multicolumn{2}{|c|}{ Cover pelontar di lengkapi dengan pelat pengarah } \\
\hline & & $\begin{array}{l}\text { - Aliran pakan ikan dalam } \\
\text { cover pelontar lebih teratur. } \\
\text { - Aliran pakan ikan lebih } \\
\text { terarah. }\end{array}$ & $\begin{array}{l}\text { - Memerlukan material yang } \\
\text { lebih banyak. }\end{array}$ \\
\hline \multirow[b]{2}{*}{3.} & \multirow{2}{*}{$\begin{array}{l}\text { Unit Pengarah } \\
\text { Desain A }\end{array}$} & \multicolumn{2}{|c|}{$\begin{array}{c}\text { Posisi poros pengarah horizontal. Poros pengarah terpisah } \\
\text { dengan poros pengaduk. }\end{array}$} \\
\hline & & $\begin{array}{l}\text { - Putaran antara poros } \\
\text { pengaduk dan pengarah } \\
\text { dapat diatur secara terpisah. }\end{array}$ & $\begin{array}{l}\text { - Biaya material lebih } \\
\text { banyak. } \\
\text { - Memerlukan motoran } \\
\text { tambahan. } \\
\text { - Proses pembuatan lebih } \\
\text { lama. }\end{array}$ \\
\hline
\end{tabular}




\begin{tabular}{|c|c|c|c|}
\hline No. & Rancangan & Kelebihan & Kekurangan \\
\hline \multirow[b]{2}{*}{3.} & $\begin{array}{l}\text { Unit Pengarah } \\
\text { Desain B }\end{array}$ & \multicolumn{2}{|c|}{$\begin{array}{c}\text { Posisi poros pengarah vertical, satu sumbu dengan poros } \\
\text { pengaduk }\end{array}$} \\
\hline & & $\begin{array}{l}\text { - Lebih hemat biaya. } \\
\text { - Proses pembuatan lebih } \\
\text { mudah. } \\
\text { - Bentuk fisik lebih menarik. }\end{array}$ & $\begin{array}{l}\text { - Putaran poros tergantung } \\
\text { pada satu motor penggerak }\end{array}$ \\
\hline \multirow{4}{*}{4.} & $\begin{array}{l}\text { Penampung pakan } \\
\text { Desain A }\end{array}$ & \multicolumn{2}{|c|}{$\begin{array}{l}\text { Penampung pakan menggunakan material stainless } \\
\text { steel. }\end{array}$} \\
\hline & & $\begin{array}{l}\text { - Lebih kuat. } \\
\text { - Tidak perlu pengecatan } \\
\text { ulang }\end{array}$ & $\begin{array}{l}\text { - Perawatan yang relative } \\
\text { lebih sulit } \\
\text { - Sulit dalam proses } \\
\text { pembuatan }\end{array}$ \\
\hline & Penampung pakan & \multicolumn{2}{|c|}{ Penampung pakan ikan menggunakan drum plastik. } \\
\hline & & $\begin{array}{l}\text { - Mudah pembuatan } \\
\text { - Mudah perawatan }\end{array}$ & $\begin{array}{l}\text { - Dimensi dari penampung } \\
\text { itu sendiri tidak dapat } \\
\text { dirubah lagi. } \\
\text { - Memerlukan pengecatan. }\end{array}$ \\
\hline \multirow{4}{*}{5.} & Rangka kaki mesin & \multicolumn{2}{|c|}{ Rangka kaki mesin berbentuk lurus } \\
\hline & & $\begin{array}{l}\text { - Proses pembuatan lebih } \\
\text { mudah dan murah. } \\
\text { - Material yang di perlukan } \\
\text { lebih sedikit. }\end{array}$ & $\begin{array}{l}\text { - Bentuk kurang menarik. } \\
\text { - Kurang kuat dalam } \\
\text { menahan dorongan saat } \\
\text { mesin beroprasi }\end{array}$ \\
\hline & Rangka kaki mesin & \multicolumn{2}{|c|}{ Rangka kaki mesin berbentuk miring } \\
\hline & & $\begin{array}{l}\text { - Lebih kuat menahan getaran } \\
\text { dan dorongan. } \\
\text { - Bentuk fisik lebih menarik. }\end{array}$ & $\begin{array}{l}\text { - Material yang diperlukan } \\
\text { lebih banyak. } \\
\text { - Proses pembuatan lebih } \\
\text { sulit dan lebih banyak. }\end{array}$ \\
\hline \multirow{4}{*}{6.} & $\begin{array}{l}\text { Cover mesin } \\
\text { Desain A }\end{array}$ & \multicolumn{2}{|c|}{$\begin{array}{l}\text { Cover mesin yang dilewati pakan ikan menggunakan pelat } \\
\text { besi. }\end{array}$} \\
\hline & & - Lebih murah & $\begin{array}{l}\text { - Mudah mengalami korosi. } \\
\text { - Memerlukan perawatan } \\
\text { yang lebih. }\end{array}$ \\
\hline & \multirow[t]{2}{*}{$\begin{array}{l}\text { Cover mesin } \\
\text { Desain B }\end{array}$} & \multicolumn{2}{|c|}{$\begin{array}{c}\text { Cover mesin yang dilewati pakan ikan menggunakan pelat } \\
\text { stainless. }\end{array}$} \\
\hline & & $\begin{array}{l}\text { - Tahan korosi. } \\
\text { - Wujud lebih menarik }\end{array}$ & - Lebih mahal. \\
\hline
\end{tabular}

\section{Keputusan}

Setelah melakukan analisa rancangan tahapan selanjutnya yaitu melakukan perbaikan dari kekurangan yang telah dijabarkan pada analisa rancangan dengan cara sebagai berikut.

\section{Evaluasi desain}

Proses pengambilan keputusan evaluasi desain adalah untuk meniadakan kekurangan pada rancangan dengan cara melakukan perbaikan untuk memperoleh hasil terbaik, beberapa bagian yang 
diperbaiki adalah :

a. Unit Pengendali

Sebelumnya pada unit pengendali mesin menggunakan timer otomatis di ganti menggunakan timer berbasis mikrokontroler, hal ini karena timer yang berbasis mikrokontroler dapat dikombinasikan menggunakan sensor-sensor pelengkap untuk mesin itu sendiri.

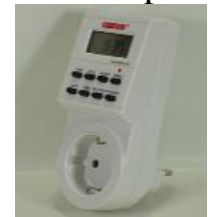

(a)

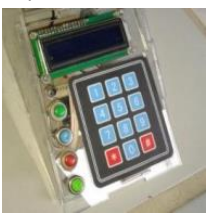

(b)

Gambar 3. Unit pengendali mesin (a) sebelum evaluasi, (b) setelah evaluasi.

b. Unit pelontar mesin

Sebelumnya pada unit pelontar, tidak dilengkapi pelat pengarah, setelah dievaluasi, pada cover pelontar dilengkapi dengan baling-baling pengarah, pelat ini difungsikan agar pergerakan pakan ikan di dalam unit pelontar lebih teratur dan memaksimalkan hasil lontaran karena pakan ikan masuk dalam area pelontar lewat samping.

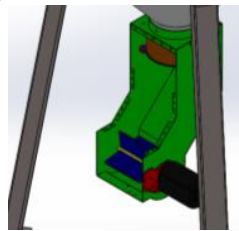

(a)

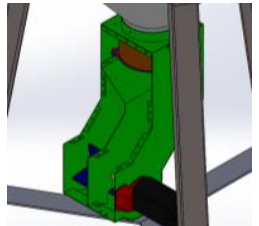

(b)

c. Unit pengarah mesin

Gambar 4. Unit pelontar (a) sebelum evaluasi, (b) setelah evalusi.

Sebelumnya pada cover unit pelontar, tidak dilengkapi dengan unit pengarah, setelah dievaluasi, pada cover pengarah dilengkapi dengan unit pengarah, pengarah ini difungsikan agar pergerakan pakan ikan dari unit penampung ke unit pelontar lebih teratur, dan kontruksi mesin tidak rumit.

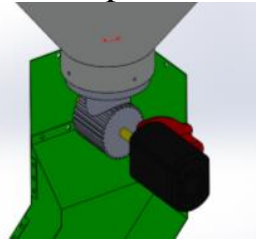

(a)

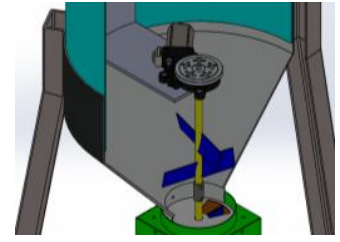

(b)

Gambar 5. Unit pengarah (a) sebelum evaluasi, (b) setelah evalusi.

d. Penampung Pakan

Sebelumnya Penampung pakan pada mesin menggunakan penampung dengan bahan stainless steel, lalu diganti menggunakan drum berbahan plastik, hal ini karena drum berbahan plastik lebih mudah dibuat, mudah perawatan, harga relatif lebih murah.

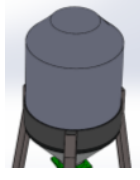

(a)

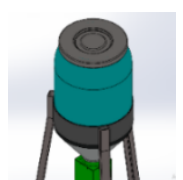

(b)

Gambar 6. Unit penampung (a) sebelum evaluasi, (b) setelah evalusi.

e. Rangka kaki mesin

Sebelumnya rangka kaki mesin menggunakan rangka kaki dengan bentuk yang lurus diganti menggunakan rangka kaki dengan bentuk yang sedikit miring, hal ini karena dengan rangka kaki mesin yang miring, kekuatan dalam menjaga keseimbangan ataupun saat mesin bekerja, lebih tinggi, dan bentuk fisik lebik lebih menarik. 


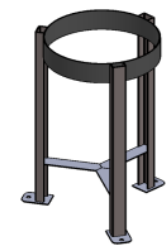

(a)

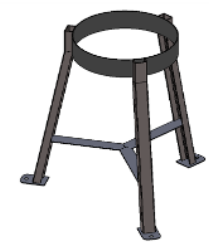

(b)

Gambar 7. Rangka kaki mesin(a) sebelum evaluasi, (b) setelah evaluasi.

f. Unit pengarah mesin

Sebelumnya pada cover unit pelontar, tidak dilengkapi dengan unit pengarah, setelah dievaluasi, pada cover pengarah dilengkapi dengan unit pengarah, pengarah ini difungsikan agar pergerakan pakan ikan dari unit penampung ke unit pelontar lebih teratur, dan kontruksi mesin tidak rumit.

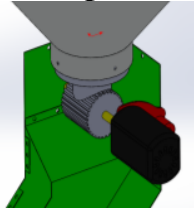

(a)

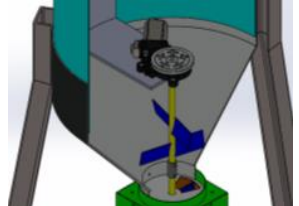

(b)

g. Cover unit pelontar mesin

Gambar 8. Unit pengarah (a) sebelum evaluasi, (b) setelah evalusi.

Sebelumnya cover mesin pada unit pelontar, menggunakan pelat besi, setelah dievaluasi, pada cover unit pelontar diganti menggunakan pelat stainless, hal ini agar pakan ikan yang diproses oleh mesin lebih bersih dan layak untuk di makan oleh ikan.

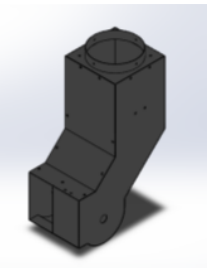

(a)

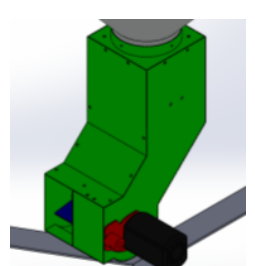

(b)

Gambar 9. Cover unit pelontar (a) sebelum evaluasi, (b) setelah evalusi.

\section{Kesimpulan Evaluasi Desain}

Dari seluruh rangkaian langkah-langkah evaluasi desain diperoleh hasil rancangan akhir berupa produk jadi mesin pelontar pakan ikan yang dapat dilihat pada Gambar 10.

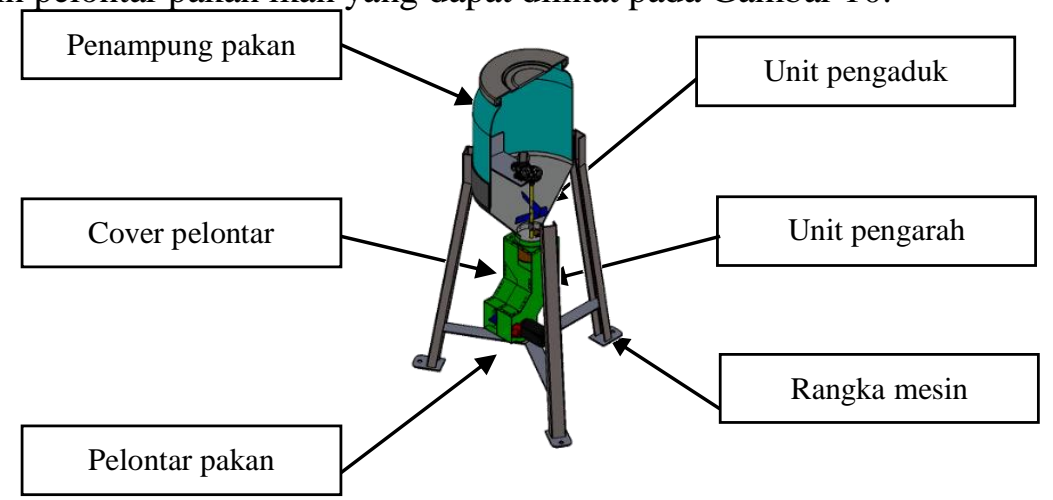

\section{Kesimpulan Dan Saran}

Gambar 10. Mesin Pelontar Pakan Ikan

Design mesin pelontar yang telah dibuat merupakan hasil pendekatan secara literatur dan survei lapangan (survey langsung di Dinas Perikanan dan di Balai Benih Ikan dimana mesin pelontar pakan ikan ini dibutuhkan). Pada mesin ini perlu proses pengembangan dan pengujian secara terus menerus.

\section{Daftar Pustaka}

Ardiwijoyo, Jamaluddin, \& Mappalotteng, A. M. (2018). Rancang Bangun Alat Pemberi Pakan Ikan

Dengan Sistem Automatisasi Berbasis Arduino Uno R3 Dengan Sistem Kendali Sms. Jurnal 
Pendidikan Teknologi Pertanian, 4, 12-20. https://doi.org/10.26858/jptp.v1i0.6228

Ferdiansyah, M. F., Rusindiyanto, R., \& Rahmawati, N. (2020). Perancangan Alat Pemberi Makan Ikan Otomatis Bagi Peternak Ikan Ditambak Dengan Metode Design for Manufacturing and Assembly (Dfma). Tekmapro: Journal of Industrial Engineering and Management, 15(1), 92-100. https://doi.org/10.33005/tekmapro.v15i1.140

Firdaus, B. A., Kridalukmana, R., \& Widianto, E. D. (2016). Pembuatan Alat Pemberi Pakan Ikan Dan Pengontrol PH Otomatis. Jurnal Teknologi Dan Sistem Komputer, 4(1), 133. https://doi.org/10.14710/jtsiskom.4.1.2016.133-138

Sifa, A., Suwandi, D., Endramawan, T., \& ... (2020). Perancangan Mesin Katrol untuk Mobilitas Mesin Pelontar Pakan Ikan. Prosiding The 11th Industrial Research Workshop and National Seminar Bandung, 26-27 Agustus 2020 Perancangan, 228-233. https://jurnal.polban.ac.id/proceeding/article/view/1999

Yenni, H., \& Benny. (2016). Perangkat Pemberi Pakan Otomatis pada Kolam Budidaya. Ilmiah Media Processor, 11(2), 171-181. 